\title{
Perceptions of Leadership Competencies and the Acquisition of Them by CEOs in Vietnamese Small Enterprises
}

\author{
Le Quan ${ }^{1}$ \\ ${ }^{1}$ University of Economics and Business, Vietnam National University, Hanoi, Vietnam \\ Correspondence: Le Quan, Human Resources Department, Vietnam National University, Hanoi, 144 Xuan Thuy \\ Street, Cau Giay Distric, Hanoi, Vietnam. Tel: 84-91-354-3330. E-mail: lequan@vnu.edu.vn
}

Received: June 25, 2014 Accepted: November 24, 2014 Online Published: January 14, 2015

doi:10.5539/ass.v11n4p17 URL: http://dx.doi.org/10.5539/ass.v11n4p17

\begin{abstract}
Leadership competencies are expected to be critical factors for Chief Executive Officers (CEOs) of small and medium sized enterprises (SMEs) to be successful and to lead their SMEs to play the role as the major driver toward economic development in Vietnam. This paper aims to understand the perceptions of CEOs of Vietnamese SMEs regarding the importance of some leadership competencies and the extent to which the competencies of knowledge, skills and attitudes have been acquired by these CEOs. This research was used them a large-scale survey and in-depth interviews method to solve those issues. The result of this research included the significant difference between the perceived importance and the level of acquisition of these competencies, particularly in Vietnam Small and Medium Entreprises. The result of this research can be seen as the important source for practioners in order to design effective training and development programs tailored for CEOs of SMEs.
\end{abstract}

Keywords: CEOs, leadership competencies, level of acquisition, perceived importance, SMEs, Vietnam

\section{Introduction}

Leadership is one of the most interested topic that attracted many researchers and practioners that concentrated huge efforts on finding the useful information for both practioners and researchers. Based on those researches, the result showed that leadership competencies can help managers to out-perform in their managerial role and contribute to organizational success. And the effective leadership is needed by all types of enterprises; however the role of leadership seems more vital in the case of small and medium-sized enterprises (SMEs) given their paramount importance in national economic development and the specific disadvantages they face when compared to their giant counterparts (Baum, Locke, \& Kirkpatrick, 1998; Vo \& Harvie, 2009; Matzler, Schwarz, Deutinger, \& Harms, 2012). In the global crisis time, the role of leadership is more and more important; they are the key person that decided the success or failure of the firms.

Vietnam has been considered as the developing country and the Vietnamese economy has experienced high growth since its reform in 1986; the key sources for this rapid development can be attributed to the private sector including SMEs and foreign invested enterprises (Harvie, 2008). The growing influence of the SMEs sector on the Vietnamese economy can be seen in different ways. The first, the total numbers of registered SMEs increased from 14,500 in 2000 to 550,000 in 2011 , representing nearly $97 \%$ of the country's total number of firms and accounting for $46 \%$ of national gross domestic products (Vietnam News, 2013). SMEs have been more efficient users of capital and generated $80 \%$ of the total employment in the period of 2000-2006 (GSO, 2008). The second is that despite this contribution, the Vietnamese SMEs sector remains small and fragile especially in comparison to the state-owned enterprises (SOEs). Private companies including SMEs do not operate on an even playing field because SOEs are still regarded as key drivers for national economic growth and enjoy preferential treatment (i.e.. access to finance) (Harvie, 2008). SMEs also face severe challenges of financial constraint, outdated technology, unstable markets and increasing competition, etc. In the 2009-2012 economic downturns in Vietnam, these challenges were compounded, illustrated by the fact that 7,000 SMEs were dissolved and 3,000 SMEs halted-production (Asiaecon, 2013). Given this context, leadership can be a critical factor for a SMEs' survival and help SMEs to play the role as the major driver toward economic development in Vietnam.

Research on the leadership field showed that the leaders can do their job effectively when they possessed the professional competences. However, little is known about the essential competencies required for effective 
leadership in Vietnamese SMEs. This paper bridges this gap and specifically aims to investigate (i) the perceptions of CEOs of Vietnamese SMEs regarding the importance of some leadership competencies (ii) the extent to which the competencies of knowledge, skills and attitudes have been acquired by the CEOs of Vietnamese SMEs. This paper also studies leadership competencies in the context of an economic downturn which has posed great challenges for Vietnamese SMEs. An economic downturn is a meaningful context for managers to re-assess their leadership and an extreme context to test their leadership skills as well. In other words, successful leadership can guide the enterprises to overcome challenges, but poor leadership can lead to the failure of SMEs. As a result of this approach, this paper is expected to contribute to the international literature which focuses on the impact of leadership on SMEs' performance and to the modest literature about leadership in SMEs in Vietnam. Additionally, the ASK analytical framework of Attitude-Skills-Knowledge together with the identified differences between the perceived importance of leadership competencies and their level of acquisition form the background to design and propose a suitable program to train and develop leadership competencies for Vietnamese's SMEs.

This paper is organized as follows. Section two is a brief review of the research in leadership competencies in Vietnam and in other parts of the world. The analytical framework and methodology is presented in section three. Section four reports the results and gives a discussion of their implications. The paper is concluded with findings and implications for further research in section five.

\section{Literature Review}

This section provides a brief introduction about the studies of the essential qualities for successful leaders under the terms of leadership competencies and effective leadership. Subsequently, leadership studies in the context of SMEs and Vietnam are reviewed.

\subsection{International Research}

Leadership competencies are defined as the characteristics, skills and behavior of leaders that contribute to the superior performance of an organization (McCleland, 1976; SHRM, 2008). The common approach in the literature is to define competencies as a specific set of attributes observed from successful performers. Hence, many studies attempted to identify the key competencies that define effective leadership (Hayes, 1979; Boyatzis, 1982; Wang \& Chen, 2002; American Management Association, 2005, etc.). This paper mainly reviews the recent literature which better reflects the contemporary leadership competencies.

In 2005, the American Management Association introduced a report on leadership. The American leadership development survey identified the top twelve leadership competencies as strategy development, communication skills, developing leaders, hiring talent, fostering creativity and innovation, etc. McCauley (2006) developed a set of competencies which was found consistent among organizations. This set was divided into three categories of leading the organization (managing change, problem solving and decision making, etc.); of leading themselves (demonstrating ethics and integrity, displaying drive and purpose, etc.); and leading others (communicating effectively, developing others, valuing diversity, etc.)

In the Asian context, specifically in China, Wang and Chen (2002) studied a managerial competencies model applied for middle managers with the strategic hierarchical job analysis and survey. The findings suggested that the essential competencies are strategic decision-making skills, relationship co-ordination, empowerment and facilitation, business monitoring and innovation. Sharing the same research purpose, Qiao and Wang (2009) used a survey of MBA students and a case study. The research found 27 competencies perceived to be "important" by respondents. The top five most important ones were accountability, team building, relationship management, continual learning and conflict management. More interestingly, the perceived importance for each competency varied among managers at different levels. In detail, competencies such as vision and strategic thinking were mentioned more frequently by CEOs; the executives assigned also a much higher value to "execution". Meanwhile, the middle managers and their subordinates gave a high ranking for co-ordination, motivating others and technical expertise. In other words, the different hierarchical levels, supervisory, managerial or executive require different competencies.

Sharing the same purpose to understand what makes a good and successful leader but stated differently, a group of studies aimed to identify essential qualities of effective leadership. Effective leadership refers to the leading and directing of subordinates to use their talents, abilities, knowledge, skills and attitudes in an effective and efficient manner to obtain the organizational targets (Yukl, 2001). Without effective leadership, the productivity, innovation and profits of the company would not only be reduced but the survival of the company would be at risk as well. Farkas and Backer (1996) observed that managers adopted the approaches of strategy, human assets, expertise and change-agent to manage their companies to achieve success. According to Collins (2001), a 
paradoxical combination of personal humility and professional will of a leader helps to make a good company a great one.

The extant literature about leadership in SMEs mainly focuses on proving the role of leadership in the performance and development of SMEs. For example, Matzler et al. (2012) statistically proved the significant and positive impact of leadership (specifically the transformational leadership style) on the growth, profitability and innovation of SMEs by analyzing a sample of 300 innovative SMEs in Austria. Similarly, Barling, Weber and Kelloway (1996) reported the significant relationship between charismatic leadership and performance. Baum et al. (1998) found the correlation between the characteristics of a CEO with the SMEs' growth measured by sales, profit and employment. On the other hand, Beaver (2003) through his observation and empirical research attributed the failure of SMEs to poor leadership and a lack of management abilities. In short, these studies reach a consensus that getting the right leadership attributes will enhance the possibility of entrepreneurial success.

\subsection{Vietnamese Research}

The subject of leadership competencies in Vietnam has been studied quite extensively with different approaches such as leadership in joint ventures, private and state-own sectors; there is one peer-reviewed study on SMEs' leadership but only examining female leaders. For example, Truong, Fredric and Dang (1998) identified the top ten characteristics of managers in Vietnamese joint ventures by revising the competency questionnaire previously used in the research project on leadership in ASEAN. 127 managers working for joint ventures in Hanoi and Ho Chi Minh City responded to the questionnaire. The top ten characteristics were: be dependable and trust worthy, be honest, have a strategic vision for the organization, have confidence in dealing with people, be logical in solving problems, be consistent in making decisions, adapt to changing working conditions, organize work time efficiently, adjust organization structure and rules to the realities of practice and accept responsibility for mistakes. However, there were some difference in the viewpoints between the Vietnamese and international managers that were surveyed. The former identified "open communication" and "being positive" as more important while the latter favored "being practical" and "ethical" as more important.

Scott and Bannon (2008) combined the interview and psychological tests' results at all levels of management other than the CEO to build a typical profile of Vietnamese managers. The sampled managers were depicted as being hard-working, ambitious and achievement-oriented. Remuneration was not a key driver in their managerial work even-though being a serious concern in the context of increasing wages. Instead, the managers surveyed expected to work with strong guidance and in a collaborating environment. Nevertheless, Vietnamese managers did not have good abilities to tolerate stress and the work-load; they also had low scores for emotional intelligence.

Vo and Harvie (2009) conducted research on SME with female leaders. Despite the traditional gender inequality, female Vietnamese entrepreneurs have narrowed their earning gap with their male counterparts while trying to maintain the balance between a new role as a breadwinner with the traditional role as a house-wife. SME entrepreneurs, in general, had difficulty in accessing financing, understanding the legal framework and business laws, accessing technology and use of IT and accessing market and government support. Female leaders had even more problems with access to finances, market information and opportunities.

Edwards and Phan (2013) conducted interviews in Hanoi and Ho Chi Minh City from 2009-2010 to provide an insight into the nature and substance of Vietnamese management in the state-owned and private sector. The study examined the managers as individuals and in their interaction with other individuals and the environment. The managers studied were portrayed with an industrious and ambitious manner manifested by long hours of working to deal with demanding issues and determination to start their own businesses. They were also avid learners who practiced continuous learning to enhance their knowledge. These characteristics were more evident in the private sectors since managers in SOEs bore less pressure due to state support; in other words, the managers of SOEs were less hard-working, less efficient and less effective. The Vietnamese managers studied tended to be people-based rather than systems-based which means they had a greater use of intuition and qualitative thinking. Management activities mainly took forms of problem-solving in the awareness of organizational and social constraints hampering the companies' activities. The authors concluded the paper with a three-force model of both constraints and opportunities that influence Vietnamese managers: tradition, modernity and the state.

\section{Analytical Framework and Research Method}

\subsection{Analytical Framework}

The ASK model has been widely used in human resources management especially in the training and 
development of personal competencies. The model is built from the three main components; A-Attitude, S-Skills and K-Knowledge (see Figure 1). The model was initially introduced by Bloom (1956) in the form of three learning domains as the holistic goal of the educational process; that is the cognitive domain (knowledge), the affective domain (attitude) and the psychomotor domain (skills). In detail, knowledge is referred to as the ability to recall data or information, to comprehend, to apply, to analyze and synthesize and to evaluate. Attitude is referred to the ability to receive and respond to phenomena, to value and organize. Skill is referred to the manual ability ranging from imitation to use, apply and to creatively apply (Dave, 1975).

From the essence of a learning taxonomy, the model has been adapted and developed to become a framework to assess leadership competencies (Campbell, 1997; Jeffrey \& Jon, 2003). For instance, Campbell (1997) developed a set of seven executive competencies from the ASK model with strategic vision, decision-making, communication, empowerment and entitlement, promotion and encouragement, and understandability. Similarly, Jeffrey and Jon (2003) developed twenty-one competencies belonging to the three ASK categories such as open-minded, tolerant, reflective, principled, communicating, cooperating, etc. In short, even though divergent, these elements of these competencies generally refer to the cluster of knowledge-skills and attitudes.

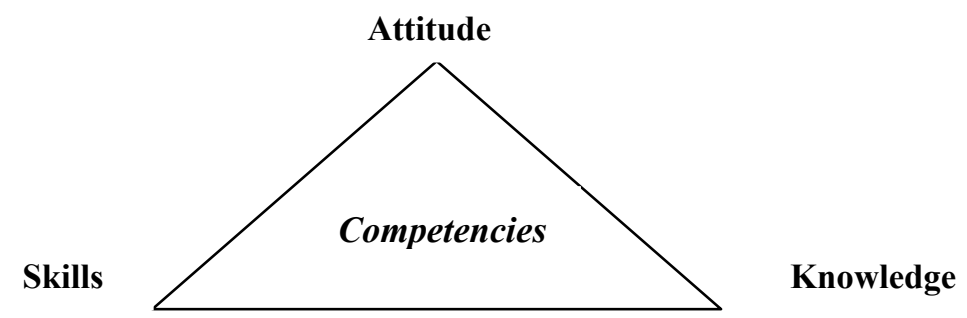

Figure 1. Analytical framework of the ASK model

Source: Bloom (1956), Campbell (1997), Jeffrey and Jon (2003)

ASK's components taking forms of definitions, elements of attributes, behavior and actions vary across the literature (Jeffrey \& Jon, 2003). The ASK's components used in this paper were adapted from the authors' previous studies on leadership development and young entrepreneur (Quan, 2004; Quan \& Phung, 2009). Accordingly, a set of 41 competencies (16 items of knowledge K1-K16, 10 items of attitude A1-A10 and 15 items of skills S1-S15) were included in the pilot surveys. From the pilot surveys conducted with 20 respondents, 26 of the 41 competencies (with its mean value being greater than 2.8/5) were selected to be included in the final and official questionnaire.

\subsection{Research Method}

The research involved two inquiry methods. The first method was a large-scale survey conducted with the CEOs of Vietnamese SMEs with an aim to understand their perceptions on the importance of leadership competencies and their self-assessment on their own acquisition of these competencies. The questionnaire contained 26 items used to measure the ASK elements needed for an effective leader in a Vietnamese SME. Respondents were asked to rate the importance of each item on a Likert scale ranging from $1=$ unimportant to $5=$ very important; then they decided the degree to which they thought they acquired the particular knowledge, skills or attitude corresponding to that competency which was also measured on a Likert scale ranging from $1=$ poor to $5=$ excellent.

The second method was a series of in-depth interviews with the CEOs of SMEs. This method was adopted to obtain a detailed explanation for the observed findings from the large-scale survey; on the other hand, it helped to elaborate the leadership competencies in the context of economic downturn. The interview was semi-structured to encourage interviewees to actively participate in the discussion but still in the pre-determined framework of queries. This approach retained reasonable objectivity and at the same time allowed an extensive exploration of the interviewees' viewpoints. More importantly, the interviews were conducted with different companies; the semi-structure form also helped to ensure a degree of consistency across the interviews.

\section{Results and Discussion}

The list of Vietnamese SMEs proposed to be surveyed came from the Vietnamese Young Entrepreneur Associations (YEA); it is note-worthy that the enterprises of the YEA are on average more successful than the average Vietnamese SMEs. The questionnaires were sent online to the selected SMEs from June to September, 2012. There were 230 valid questionnaires returned from SMEs mainly operating in big cities such as Hanoi, Ho 
Chi Minh City, Danang, etc. (80\%) and in the service and trading sector (72\%). In terms of capital size, over half of the surveyed SMEs have legal capital under 10 billion VND and only 17\% under 1 billion VND. Most of the respondents were well educated with $15.56 \%$ holding master degrees and $70.43 \%$ holding bachelor degrees; their ages were equally split between two main groups, $30-40$ years old (35\%) and $40-50$ years old (30\%). Notably, $92 \%$ of the CEOs surveyed were also the owners of their companies holding over $10 \%$ of the shares of the company. Then, thirty personal in-depth interviews were conducted to elaborate the survey's results.

\subsection{Attitudes}

Regarding the survey of attitudes (see Table 1), in terms of perceived importance, the CEOs surveyed ranked "Broad Vision" at the top list; next came Patience, Creativity, Risk-taking; at the bottom of the list were Adaptability and Meticulousness. As also seen the small difference between the minimum and maximum mean value, respondents perceived all attitudes as having moderate importance. Regarding the acquisition level, Patience was the attitude that CEOs of SMEs in Vietnam were most confident about. Risk taking, creativity and adaptability were ranked at the second level of confidence in the CEO's self-assessment. More noteworthy, broad vision, even-though being assigned the highest importance, had the lowest acquisition mean value.

Broad vision is quite relevant to a CEOs' position as they are in charge of developing and implementing organizational strategies. The considerable difference in its importance and acquisition mean value could be attributed to the current low economic growth of Vietnam. The interviewees consistently claimed that they needed a broad vision to see through the current turbulence; they were expected to overcome contemporary challenges but also stick to the long-term strategy. Nevertheless, the CEOs interviewed also found it too difficult to think broadly and be strategically-minded as they were struggling to keep their business alive in the short-term. This to some extent reflects the cautious (even pessimistic) viewpoints of CEOs over the foreseeable recovery of the economy.

Table 1. Essential attitudes for effective leadership in Vietnamese SMEs

\begin{tabular}{lllll}
\hline Attitude & Mean & $\begin{array}{c}\text { Acquisition } \\
\text { Std. Deviation }\end{array}$ & Mean & $\begin{array}{c}\text { Importance } \\
\text { Std. Deviation }\end{array}$ \\
\hline A6: Broad vision & 3.0145 & .67979 & 3.6957 & .83769 \\
A2: Patience & 3.7164 & .786827 & 3.5789 & 1.03587 \\
A3: Creativity & 3.4273 & 1.05872 & 3.5614 & .97579 \\
A1: Risk-takingness & 3.4594 & 1.04323 & 3.5000 & .77687 \\
A4: Adaptability & 3.321 & .89552 & 3.4386 & 1.07871 \\
A5: Meticulousness & 3.289 & 1.03247 & 3.3246 & 1.04940 \\
\hline
\end{tabular}

Source: Authors' calculation

Patience was needed by entrepreneurs in different aspects. Because of limited resources and finances, it is impossible for SMEs to obtain great business success instantly. In the case of Vietnam, as SMEs do not play on an even field with SOEs, patience also helped leaders to tolerate the unfavorable external conditions such as the administrative and bureaucratic procedures and system. In the context of economic difficulties, patience was needed more by CEOs to wait for progress to happen at the right time. On the other hand, a CEO's hastiness is likely to result in a wrong decision made for medium and long-term issues. Patience is also manifested by the persistence of investment in human resources' training and development even during an economic downturn.

Creativity is considered to be quite important as any proposed ideas of the CEOs in terms of products, process and market could enhance the competitive advantage of SMEs. In practice, innovative ideas of SMEs mainly came from the top leaders; owing to the limited capacity of personnel, innovation was hardly discussed among employees. This explains why SME's CEOs were quite confident of their creativity. A risk-taking attitude in this paper's context was interpreted to be that CEOs were moderately tolerant to errors and failures of their employees to some extent. The underlying reasons, revealed from the in-depth interviews, were that CEOs wish to create an innovative culture in their companies; tolerance for failures was regarded to motivate and encourage employees to make new ideas.

Meticulousness was ranked at another extreme with broad vision in the importance rank; it is not necessarily refer to the opposite relationship. Due to small and medium companies' size, Vietnamese CEOs are also involved in a hands-on role in the company and make lower-level decisions such as hiring staff, choosing suppliers, etc. Therefore, they were expected to care about and participate in some detailed and specific operational tasks of the company. Adaptability is quite relevant in the developing and fast changing economy in Vietnam. CEOs can adapt 
their minds and their companies' strategy toward new opportunities and challenges. Adaptability also helps CEOs to come to terms with incomplete infrastructure and SMEs' supporting scheme of the transitional economy.

\subsection{Knowledge}

Regarding the results and perceived importance of knowledge (see Table 2), all types of knowledge were rated as "moderately important" (mean value of 3.33-3.73) except for strategic management which was weighted as "important" (mean value of 4.06). In the former group, accounting/finance, HR management, marketing, business line, international integration, technology, culture-society, legislation and foreign languages were ranked in descending order of importance. In respect to the level of acquisition, the understanding of legislation-politics, business lines, culture and society were assessed to be quite close to the "good" level. The group of knowledge being "fair" to "average" included marketing, HR management and strategic management, accounting/finance, foreign languages and international integration.

The perceived importance of strategic management knowledge together with broad vision attitude consistently proves that CEOs of Vietnamese SMEs assigned high value to the competencies influencing the long-term and strategic development pathway of their companies. Unfortunately, there exists a significant gap between the importance and the acquisition means of both knowledge and attitude categories. It can be possibly interpreted that due to a lack of knowledge in strategic management, CEOs were not confident in their broad vision assessment. In the in-depth interviews, CEOs of SMEs also raised another fact that they were too busy keeping their companies running on a day-to-day basis; accordingly, strategic leadership was not always high on the agenda especially during times of economic hardship. This paper's findings are quite different from Truong et al. (1998)'s which found a strategic vision of managers for their organizations. Truong et al. (1998) sampled a larger group of managers which included more than SMEs' CEOs; besides, at the beginning of the twenty-first century, the Vietnamese economy and its enterprises were quite eager to welcome more prospective economic opportunities.

Table 2. Essential knowledge for effective leadership in Vietnamese SMEs

\begin{tabular}{lllll}
\hline Knowledge & Mean & $\begin{array}{c}\text { Acquisition } \\
\text { Std. Deviation }\end{array}$ & Mean & $\begin{array}{c}\text { Importance } \\
\text { Std. Deviation }\end{array}$ \\
\hline K10: Strategic management & 2.9367 & .82314 & 4.0696 & .83296 \\
K8: Accounting/Finance & 2.8385 & .96451 & 3.7368 & .92019 \\
K7: Human resource management & 2.9635 & .90219 & 3.7105 & .89761 \\
K9: Marketing & 2.9872 & .81691 & 3.6435 & .86858 \\
K1: Business lines & 3.8147 & .76585 & 3.5043 & 1.14742 \\
K5: International integration & 2.7034 & 1.24712 & 3.5043 & .91922 \\
K6: Technology & 3.1467 & .82636 & 3.4231 & .85344 \\
K4: Culture and Society & 3.8305 & .86347 & 3.4211 & .96544 \\
K3: Legislation/Politics & 3.9165 & .74235 & 3.3565 & .88846 \\
K2: Foreign Languages & 2.8224 & .92192 & 3.3304 & .73255 \\
\hline
\end{tabular}

Source: Authors' calculation

Vo and Harvie (2009) reported the legal framework as one of SMEs' challenges while the paper's surveyed SMEs' CEOs were most confident of their knowledge of legislation and politics. To partially explain for this difference, the paper's sample as stated previously contains SMEs that were on average more successful than an average Vietnamese SME. From the interviews, CEOs regarded their understanding of legislation as competitive advantages. On the one hand, they could take advantage of some SMEs-supporting policies from the governments of some international organizations (i.e. investment and export promotion, credit access, information and human resources training and consultancy, etc.). On the other hand, regulatory understanding would help to ease the pressure and negative impact from the vague and frequently changing legal policies.

Vietnamese SMEs' CEOs were also accountable for managing the overall operations and resources of companies. Therefore, they tended to well acquire functional knowledge such as marketing, HR management, accounting and finance and technology to raise the operational efficiency and effectiveness of their companies. The grasp of functional knowledge was also consistent with the meticulousness level of SMEs' CEOs.

All sampled SMEs were domestic companies without foreign participation in terms of investment and human resources. This explains why surveyed CEOs were quite confident on their understanding of culture and society. 
It is, however, noteworthy that foreign languages and international integration ranked at the bottom in terms of level of acquisition. SMEs' CEOs possibly had no plan to expand their business beyond the national boundaries or involve foreign financial and human resources in organization development at least in the short-term.

\subsection{Skills}

For the skills' surveyed (see Table 3), in terms of perceived importance, CEOs assigned the highest importance value to leadership skills. Other skills were weighted in the range of 3.78-3.45; a list in descending order includes thinking, team-building, interpersonal, planning, decision-making, time management, communication, office management and meeting skills. Regarding the level of acquisition, communication skills were ranked at the top of the list followed by interpersonal skills, leadership skills, thinking, decision-making, team-building and office management skills; the skills of time management, planning and meeting skills ranked at the bottom.

Leadership skills include the ability to build power, motivate and lead others to meet objectives. The surveyed CEOs valued this essential skill of a leader as high as the broad vision attitude and strategic management knowledge. The in-depth interviews also revealed that leadership and management skills were believed to be learnt through experience especially among young and middle-aged CEOs. This is a good sign to expect that there is a high possibility to close the gap between importance and acquisition mean of leadership in the near future. Besides, leadership skills seemed to be more essential in the context of economic difficulties as CEOs were expected to enhance the working morale and unite their employees to work closely toward mutual targets.

Table 3. Essential skills for effective leadership in Vietnamese SMEs

\begin{tabular}{llclc}
\hline \multirow{2}{*}{ Skills } & \multicolumn{2}{c}{ Acquisition } & \multicolumn{2}{c}{ Importance } \\
& Mean & Std. Deviation & Mean & Std. Deviation \\
\hline S8: Leadership skills & 3.2402 & .75314 & 3.9823 & .84309 \\
S1: Thinking skills & 3.2348 & .72867 & 3.7857 & .91258 \\
S9: Team-building skills & 3.191 & .87157 & 3.6549 & .77483 \\
S10: Interpersonal skills & 3.2763 & .91034 & 3.6417 & .74465 \\
S3: Planning skills & 2.849 & .85430 & 3.6372 & .91469 \\
S4: Information analysis and decision making & 3.2354 & .92128 & 3.6140 & 1.02402 \\
skills & 2.9578 & .77523 & 3.5893 & .82074 \\
S6: Time management skills & 3.509 & .74445 & 3.5575 & .75352 \\
S2: Communication skills & 3.0247 & .84391 & 3.4867 & .76728 \\
S7: Office management skills & 2.7932 & .89207 & 3.4561 & .87188 \\
S5: Meeting skills & \multicolumn{3}{c}{} \\
\hline S6ring
\end{tabular}

Source: Authors' calculation

Communication skills were highly weighted as important and self-assessed by the surveyed CEOs as in other studies of Truong et al. (1998) and Qiao and Wang (2009). CEOs of SMEs serve as the main point of communication between the board of directors and the organization; they are strategic decision-makers, at the same time, responsible for translating organizational strategy into actions and share these with subordinates and employees. These roles explain the essential importance of communication skills. Another skill, team-building, was also assessed at average level. Due to the small size of staff and the inherent collectivistic manner of Vietnamese, CEOs of SMEs had favorable conditions to set up a cooperative and productive group of workers. Interpersonal skill was also assessed as strength of Vietnamese CEOs. In a relationship-based society like Vietnam, this skill would help CEOs to maintain good relationships with external stakeholders such as finance providers, customers and governmental authorities.

Being responsible for managing the organization's general operations, CEOs inevitably think and make important decisions all the time. Under the pressure to decide in an effective and timely manner, interviewed CEOs suggested to down-scale complicated decisions to simpler steps via some frequently used frameworks such as SWOT or pros-cons. They also searched internally and externally for discussion, recommendations and voting for important issues. Planning skills, time management and meeting skills were weighted with the lowest acquisition mean value. Interviewed CEOs once again complained on the trade-off between time spent on operational and strategic issues. Some CEOs even found them spending most of their official working hours on meeting, thus they usually had to work extra-hours to do their management-related tasks. Some solutions were also suggested such as better planning their personal working schedules as well as exercising delegation and assignment to their subordinates. 


\section{Conclusion and Implications}

\subsection{Conclusion}

Based on the theoretical perspective, the result of this research has been huge contributed on ledership field. There is the significant difference between the perceived importance and the level of of competencies' acquisition of CEOs of Vietnamese SMEs. The result showed all competencies were evaluated from "moderately important" to "important"; most of their ratings were close to the higher scale. In contrast, the current level of competencies' acquisition ranged from "average" to "good" with some items falling below the lower scale. Regarding three categories of the ASK model, skills gained the group's highest average mean value of perceived importance; next comes knowledge and attitude. Conversely, the group of attitude wais self-assessed to be acquired with the most confidence from CEOs. As seen quite interestingly, the highly perceived important group of competencies was also the one being acquired by the surveyed CEOs at least.

Interestingly, the result indicated that CEOs of Vietnamese SMEs assigned high value of importance to broad vision attitude, strategic management knowledge and leadership skills which were relevant to their executive roles and the long-term development pathway of their enterprises. However, these competencies were not assessed at good level of acquisition. Instead, CEOs of Vietnamese SMEs were better evaluated with their meticulousness and their understanding of functional knowledge such as marketing, business lines, technology and accounting-finance, etc. The finding, to some extent, reflects the fact that Vietnamese CEOs were also actively involved in hands-on and operational tasks. This finding is also reinforced by the interviews, under the impact of current economic difficulty, SMEs'. The result can be explained by the SMEs characteristic. Because of small size, limited resources: limited financial resources and human resources, etc. As the result, the CEOs not only do their strategic roles but also they have to do more operational tasks. Consequence, they have to pay more attention on strengthening their operational competences.

Another attractive point from this research showed that CEOs of Vietnamese SMEs were confident with their acquisition of patience, legislation-politics knowledge, communication and interpersonal skills. Patience helped CEOs avoid hastily making wrong decisions and waiting for the organizational progress and national economic recovery to happen at the right time. Understanding of the regulatory framework was beneficial to take advantage of governmental and foreign supporting scheme and lessen the negative impact of incomplete and constantly changing policies. Communication and interpersonal skills were essential for CEOs to maintain good relationship with internal and external stakeholders. Those results have been revealed the important of the combination between the leader's characteristic ("born leader"), the learning process of leaders and their situations that they have to cope with.

\subsection{Implications}

There are some implications drawn from the paper's findings. The well-acquired competencies identified in the paper may provide a relevant basis for the selection of potential leaders. For the incumbent CEOs, the assessment framework of leadership competencies is beneficial for them to plan their professional growth and development. More importantly, the analysis of competencies will help to design effective training programs tailored for CEOs of Vietnamese SME. For instance, strategic-related competencies with high difference in the perceived importance and level of acquisition should be prominently addressed in the training content. The least confident level of acquisition of foreign languages, international integration, planning and time management skills also identify the specific area of the training programs. In the further research, a training program specifically addressing these weaknesses will be proposed.

\section{References}

American Management Association. (2005). Leading into the future: A global study of leadership 2005-2015. Retrieved February, 2014, from http://www.amanet.org/HRILeadershipSurv05.pdf

Asiaecon. (2013). 7,000 Vietnamese SMEs bankrupt amid global crisis. Retrieved February, 2014, from $\mathrm{http}: / / \mathrm{www}$.asiaecon.org/regions/get_news_item/vietnam/12722

Barling, J., Weber, T., \& Kelloway, E. K. (1996). Effects of transformational leadership training on attitudinal and financial outcomes: A field experiment. Journal of Applied Psychology, 81, 827-832. http://dx.doi.org /10.1037/0021-9010.81.6.827

Baum, I. R., Locke, E. A., \& Kirkpatrick, S. A. (1998). A longitudinal study of the relation of vision and vision communication to venture growth in entrepreneurial firms. Journal of Applied Psychology, 83, 43-54. http://dx.doi.org/10.1037/0021-9010.83.1.43

Beaver, G. (2003). Small business: Success and Failure. Strategic Change, 12(3), 115-122. http://dx.doi.org/10. $1002 /$ jsc. 624 
Bloom, B. S. (1956). Taxonomy of Educational Objectives, Handbook I: The Cognitive Domain. New York: David McKay Co Inc.

Boyatzis, A. R. (1982). The Competent Manager: A Model for Effective Performance. John Wiley \& Sons.

Campbell, J. P. (1997). The cutting edges of leadership. Southern Illinois University Press.

Collin, J. (2001). Good to great. New York: Harper Business.

Dave, R. H. (1975). In R. J. Armstrong (Ed.), Developing and Writing Behavioral Objectives. Tucson, Arizona: Educational Innovators Press.

Edwards, V., \& Phan, A. (2012). Managers and management in Vietnam 25 years of economic renovation. Routledge Studies in the growth of Economies of Asia. London: Routledge Taylor \& Francis Group.

Farkas, C. M., \& Backer, P. D. (1996). Maximum leadership. New York: Holt and Company.

General Statistical Office-GSO. (2008). Vietnam Enterprises Survey 2008. Retrieved February, 2014, from http://catalog.ihsn.org/index.php/catalog/3209/sampling

Harvie, C. (2008). SME development strategy in Vietnam. In C. Harvie, \& B. C. Lee (Eds.), Small and Medium Sized Enterprises in East Asia: Sectoral and regional Dimensions, Studies of Small and Medium Sized Enterprises in East Asia (pp. 200-239). Cheltenham, United Kingdom: Edward Elgar.

Hayes, J. (1979). A new look at managerial competence: The AMA model for worthy performance. Management Review, 59, 2-3.

Jeffrey, D. H., \& Jon, J. F. (2003). Leadership competencies: Are we all saying the same thing. Proceeds of $45^{\text {th }}$ Annual Conference of the International Military Testing Association. Pensacola, Florida. Retrieved from http://www.drtomlifvendahl.com/Leadershipcompetencies.pdf

Matzler, K., Schwarz, E., Deutinger, N., \& Harms, R. (2008). The Relationship between Transformational Leadership, Product Innovation and Performance in SMEs. Journal of Small Business \& Entrepreneurship, 21(2). Special Issue: A Panoramic Overview Of Entrepreneurship: Insights From Different Regions Of The World.

McCauley, C. (2006). Developmental assignments: Creating learning experiences without changing jobs. Greensboro, N.C: Center for Creative Leadership Press.

McCleland, D. (1976). A Guide to Job Competency Assessment. McBer, Boston, MA.

Qiao, J. X., \& Wang, W. (2009). Managerial competencies for middle managers: Some empirical findings from China. Journal of European Industrial Training, 33(1), 69-80. http://dx.doi.org/10.1108/030905909109 24388

Quan, L. (2004). Qualities of Vietnamese young entrepreneurs. Journal of Commerce Science, 13.

Quan, L., \& Phung, T. M. L. (2009). Competencies of SMEs' managers in Nam Dinh province. Journal of Commerce Science, 29.

Scott, P., \& Bannon, W. (2008). Managing for success in Vietnam. Hanoi: Young Publisher.

SHRM-Society for human Resources Management. (2008). Leadership Competencies. Retrieved February, 2014, from http://www.shrm.org/Research/Articles/Articles/Pages/LeadershipCompetencies.aspx

Truong, Q., Fredric, W. S., \& Dang, T. K. C. (1998). Effective leadership in joint ventures in Vietnam: A cross-cultural perspective. Journal of Organizational Change Management, 11(4), 357-372. http://dx.doi. org $/ 10.1108 / 09534819810225904$

Vietnamnews. (2013). ADB provides $\$ 50 \mathrm{~m}$ loan to support SMEs. Retrieved February, 2014, from http://vietnamnews.vn/society/248034/adb-provides-50m-loan-to-support-smes.html

Vo, A., \& Harvie, C. (2009). The changing face of women managers in small and medium sized enterprises in Vietnam. In C. Rowley, \& Q. Truong (Eds.), The changing face of Vietnamese management (pp. 158-182). London: Routledge Taylor \& Francis Group.

Wang, Z. M., \& Chen, M. K. (2002). Managerial competency modeling: A structural equations analysis. Psychological Science, 6, 420-428.

Yukl, G. A. (2001). Leadership in organization (5th ed.). Englewood Cliffs: Prentice Hall.

\section{Copyrights}

Copyright for this article is retained by the author(s), with first publication rights granted to the journal.

This is an open-access article distributed under the terms and conditions of the Creative Commons Attribution license (http://creativecommons.org/licenses/by/3.0/). 